\title{
OPTIMASI PARAMETER QUENCHING DAN TEMPERING PADA HRP STEEL LOKAL SEBAGAI BAJA ARMOR NASIONAL
}

\author{
Yurianto $^{1}$, Pratikto ${ }^{2}$, Rudy Soenoko², Wahyono Suprapto ${ }^{2}$ \\ ${ }^{1}$ Departemen Teknik Mesin FT UNDIP Jl. Prof. Sudarto, SH Semarang Jawa tengah Indonesia \\ 2Jurusan Teknik Mesin FT UB JI. MT. Haryono Malang Jawa Timur Indonesia \\ Nomor Telepon 0247460059 \\ E-mail: yurianto@undip.ac.id
}

\begin{abstract}
Armor steel is a high strength and hardness steel that used to protect against damage by an object, individual or vehicle from direct pressure of projectile. In Indonesia, this steel is made of hot rolled plate steel and heat treated by quench and temper, the result is Quenched \& Tempered Steels used for military components (such as main batle tank and the like) and commercials (such as making heavy equipment and others) manufactures. The problems of this study can be formulated by "What are the optimum hardness number and toughness that can be achieved by HRP Steel made in Indonesia?". This study aims to find of optimum parameter of quenching and tempering heat treatment to hardness and toughness of HRP Steel made in Indonesia. The method of this study to combining quench and temper heat treatment by optimizing austenitization temperature; holding time of austenization; tempering temperature; holding time of tempering. Optimization are done by using Minitab 16 Software. The result of study are austenitization temperature $900{ }^{\circ} \mathrm{C}$; holding time of austenization 45 minutes; tempering temperature $125{ }^{\circ} \mathrm{C}$; holding time of tempering 45 minutes; hardness prediction 569,96 HVN (and hardness influenced by tempering). For austenitization temperature $900^{\circ} \mathrm{C}$; holding time of austenization 45 minutes; tempering temperature $175{ }^{\circ} \mathrm{C}$; holding time of tempering 45 minutes; prediction of toughness $30.50 \mathrm{~J}$ (and toughness influenced by tempering).
\end{abstract}

Keywords: austenitization, quenching, tempering, hardness, toughness.

\section{PENDAHULUAN}

Armour steel adalah baja kekuatan dan kekerasan tinggi untuk melindungi benda dari kerusakan dari tekanan langsung proyektil selama pertempuran. Di Indonesia armour steel dibuat dari hot rolled plate steel (HRP Steel) buatan Indonesia yang diperlakukan panas quench + temper, dan hasilnya $Q \& T$ Steel (Quenched \& Tempered Steel).

Sifat mekanik baja paduan rendah dapat ditingkatkan dengan penghalusan butir austenite [1]. Zona austenite berada diatas garis $\mathrm{Ar}_{3}$ (kira-kira titik d Gambar 1) untuk HRP Steel dihitung dengan rumus berikut [2], $\operatorname{Ar} 3\left({ }^{\circ} \mathrm{C}\right) \sim 910$ - (310C) - (80Mn) -

$$
\text { (80Mo) - (55Ni) - (20Cu) - (15Cr) }
$$

Selama quenching terjadi transformasi struktur austenite ke martensite. Mulai terbentuknya struktur martensite dihitung:[2],

$$
\begin{aligned}
M s & \left({ }^{\circ} \mathrm{C}\right)=561-474 \mathrm{C}-33 \mathrm{Mn}- \\
& 17 \mathrm{Ni}-17 \mathrm{Cr}-21 \mathrm{Mo}
\end{aligned}
$$

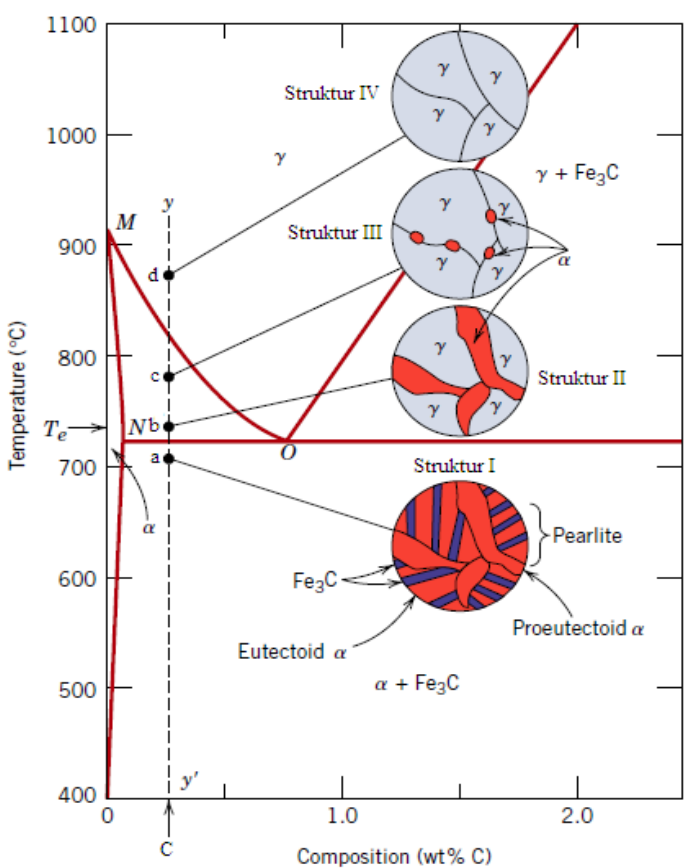

Gambar 1. Diagram $\mathrm{Fe}_{3} \mathrm{C}$ [3] 
Rumus (2) digunakan pada baja dengan carbon $0.2 \%-0,8 \%$.

Akhir pembentukan struktur martensite adalah,

$M_{f}=175 \stackrel{\circ}{\circ} \mathrm{C}-265 \stackrel{\circ}{\circ} \mathrm{C}$ dibawah $\mathrm{M}_{\mathrm{s}}$

Akhir quenching menghasilkan baja yang keras oleh struktur martensite dan sulit di manufaktur, untuk itu perlu sedikit pelunakan (kekerasan sedikit menurun) dengan tempering untuk meningkatkan keliatan (ductility).

Tempering menghasilkan karbida yang tersebar dalam matriks ferritic yang sedikit mirip dengan martensite asli [4]. Temper quenched steels pada temperatur $(148-205){ }^{\circ} \mathrm{C}$ akan terjadi penurunan kekerasan dan internal stress [4]. Temper praktis di industri dilakukan pada $150^{\circ} \mathrm{C}$ [5]. Profil kekerasan baja setelah temper, struktur mikronya lebih homogen [6]. Meningkatnya waktu temper, penghalusan menurun secara signifikan [7].

Energi impact Charpy dihitung dengan rumus [3],

$$
E=W \times R \times(\cos \beta-\cos \alpha)
$$

(4)

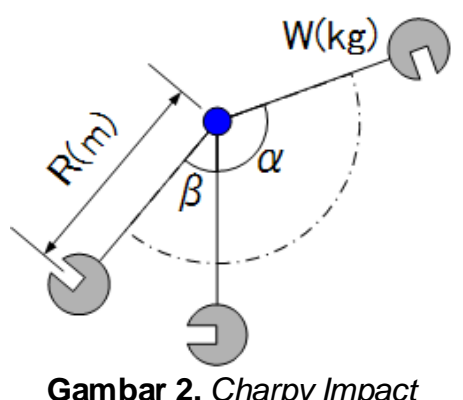

Dalam hal ini (Gambar 2),

$\mathrm{W}=$ Berat hammer, $\mathrm{kg}$.

$\mathrm{R}=$ Jarak pusat hammer, $\mathrm{m}$.

$\alpha=$ Sudut angkat sebenarnya, $\left({ }^{\circ}\right)$

$\beta=$ Sudut setelah kontak ( $\left.{ }^{\circ}\right)$.

Rumusan masalah penelitian ini adalah "Berapa angka kekerasan dan ketangguhan optimum yang bisa dicapai oleh HRP Steel buatan Indonesia?.

Penelitian ini bertujuan untuk mencari kekerasan dan ketangguhan optimum HRP Steel buatan Indonesia setelah proses quench dan temper.

\section{METODE PENELITIAN}

Metode yang digunakan adalah optimasi temperatur austenite, austenite holding time dan temperatur temper. Parameter quenching, tempering dan tahapan penelitian ditunjukkan dalam Gambar 3 dan Gambar 4. Pengolahan data dilakukan dengan Minitab 16 Software.

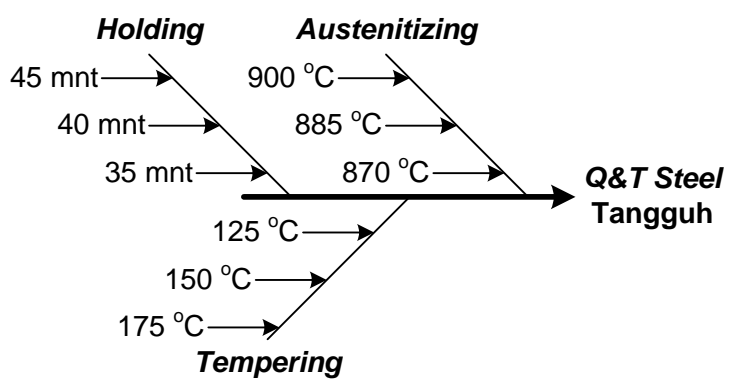

Gambar 3. Pemilihan level

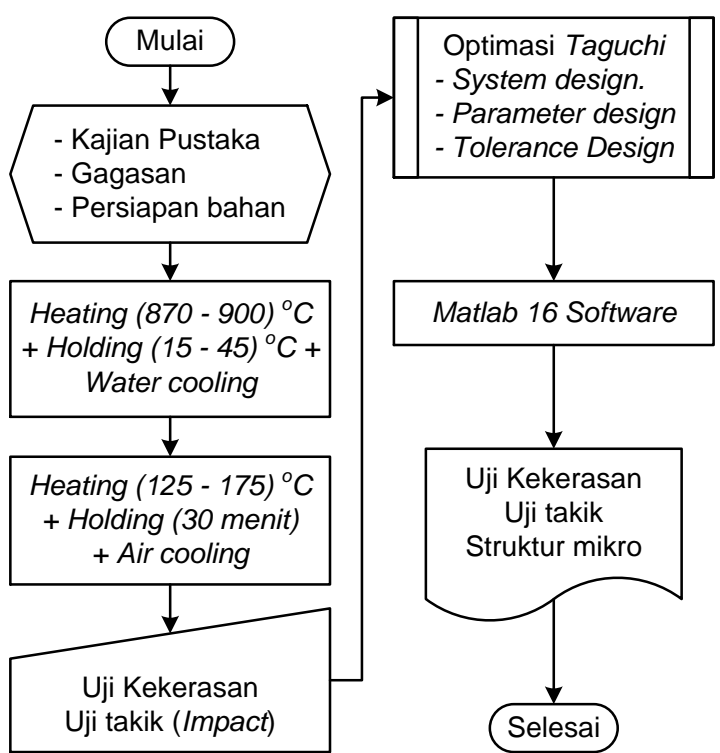

Gambar 4. Diagram alir jalannya penelitian

Tabel 1 HRP Steel tebal $10 \mathrm{~mm}$

\begin{tabular}{ccccc}
\cline { 1 - 3 } Unsur & \% berat & & Unsur & \% berat \\
\cline { 1 - 2 } \cline { 5 - 6 } $\mathrm{Al}$ & 0,03785 & & $\mathrm{~Pb}$ & 0,00825 \\
$\mathrm{C}$ & 0,29342 & & $\mathrm{Si}$ & 0,32985 \\
$\mathrm{Cr}$ & 0,55029 & & $\mathrm{~S}$ & 0,00810 \\
$\mathrm{Cu}$ & 0,08337 & & $\mathrm{Tin}$ & 0,00339 \\
$\mathrm{Fe}$ & 96,7625 & & $\mathrm{Ti}$ & 0,00439 \\
$\mathrm{Mn}$ & 1,41218 & & $\mathrm{~V}$ & 0,01473 \\
$\mathrm{Mo}$ & 0,19303 & & $\mathrm{~W}$ & 0,00951 \\
$\mathrm{Ni}$ & 0,27877 & & $\mathrm{Zn}$ & 0,00378 \\
$\mathrm{P}$ & 0,01425 & & $\mathrm{Zr}$ & 0,00116
\end{tabular}


HASIL DAN PEMBAHASAN

Unsur yang terkandung

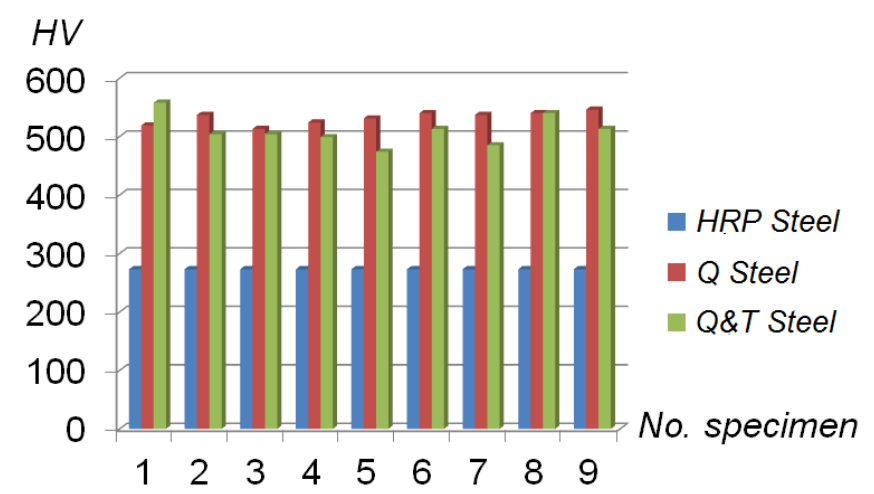

Gambar 5. Perbandingan kekerasan HRP Steel, Q Steel dan Q\&T Steel

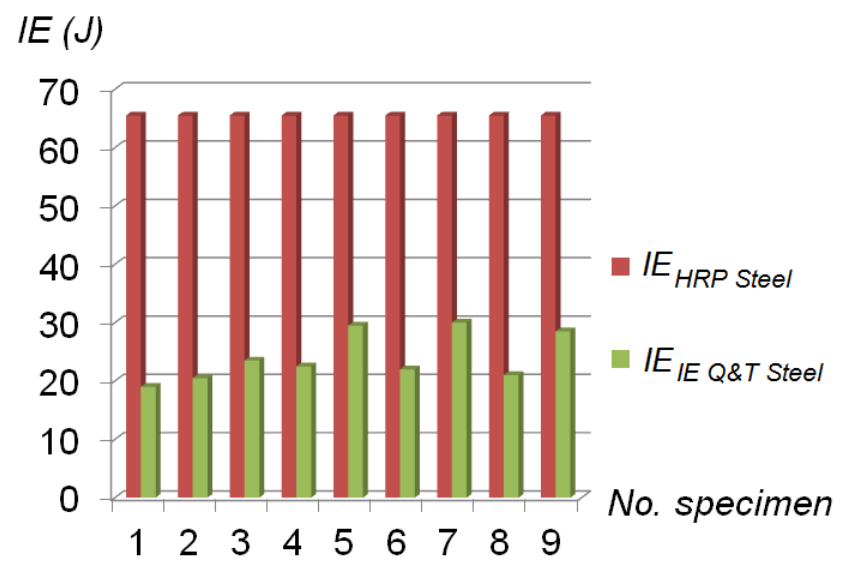

Gambar 6. Perbandingan energi yang diserap HRP Steel, Q Steel dan Q\&T Steel

Hasil observasi spectrometer pada HRP kedalam air yang menghasilkan tegangan sisa Steel (Tabel 1). Unsur carbon (C) 0,292342\%, tekan, atau pengerasan mekanis.

baja adalah heat treatable steel.

Setelah quenching dilakukan temper de-

Berdasarkan unsur kimia yang terkandung, ngan temperatur yang divariasikan. Temperatur mulai dan berakhirnya terbentuk struktur marten- temper dipilih dibawah $\mathrm{MF}_{\mathrm{F}}$, hal ini dimaksudkan site dapat dicari. Struktur martensite sangat untuk menghindari berkurangnya struktur penting dalam pengerasan baja.

Temperatur $A r_{3} T_{A r 3} \approx 665^{\circ} \mathrm{C}$, austenitisasi diatas $665^{\circ} \mathrm{C}$. Temperatur $M_{s,} \approx 357^{\circ} \mathrm{C}$. Temperatur $M_{F}=91{ }^{\circ} \mathrm{C}$ sd. $182{ }^{\circ} \mathrm{C}$ dibawah $M s$. Temper dibawah $M s$, dan bersifat mereduksi tegangan sisa dan tidak mengurangi struktur martensite.

\section{Kekerasan}

Setelah quench dan temper, kekerasan hanya oleh struktur matensite, atau kekerasan metalurgis.

Pengerasan lain juga terjadi karena adanya pemuaian ketika pemanasan ke temperatur austenite dan penyusutan ketika quenching martensite dan hanya mereduksi tegangan sisa yaitu $125^{\circ} \mathrm{C}, 150^{\circ} \mathrm{C}$ dan $175^{\circ} \mathrm{C}$.

Hasil observasi kekerasan terhadap specimen sebelum dan sesudah perlakuan panas quench dan temper, masing-masing diplot dalam bentuk diagram batang (Gambar 5). Nampak perbedaan kekerasan HRP Steel, Q Steeldan $Q \& T$ Steel setelah proses tempering.

\section{Impact Energy (IE)}

Oleh karena yang diinginkan adalah $Q \& T$ Steel, maka impact energy dibandingkan dengan HRP Steel (lokal). Artinya dengan cara mengoptimasikan 3 (tiga) titik temperatur pemanasan (heating) diatas garis Ars. 
Pada Gambar 6 nampak bahwa HRP Steel setelah mengalami perlakuan panas quench dan setelah selesai dilanjutkan dengan perlakuan panas temper (yang menghasilkan Q\&T Steel) mengalami penurunan impact energy (IE) yang cukup significant.

Tabel 2 desain parameter dan level taguchi

\begin{tabular}{cccc}
\hline$P$ & \multicolumn{3}{c}{$L$} \\
\cline { 2 - 4 } & 1 & 2 & 3 \\
\hline $\mathrm{A}$ & 870 & 885 & 900 \\
$\mathrm{H}$ & 15 & 30 & 45 \\
$\mathrm{~T}$ & 125 & 150 & 175 \\
\hline
\end{tabular}

Tabel 3 Orthogonal array L9

\begin{tabular}{llll}
\hline \multirow{2}{*}{$P$} & \multicolumn{3}{c}{ Faktor } \\
\cline { 2 - 4 } & $A$ & $H$ & $T$ \\
\hline 1 & 1 & 1 & 1 \\
2 & 1 & 2 & 2 \\
3 & 1 & 3 & 3 \\
4 & 2 & 1 & 2 \\
5 & 2 & 2 & 3 \\
6 & 2 & 3 & 1 \\
7 & 3 & 1 & 3 \\
8 & 3 & 2 & 1 \\
9 & 3 & 3 & 2 \\
\hline
\end{tabular}

Tabel 4 . Kekerasan dan signal / noise

\begin{tabular}{cccccc}
\hline \multirow{2}{*}{$E$} & \multicolumn{3}{c}{ Replikasi } & $\bar{H}$ & S/N \\
\cline { 2 - 4 } & $H_{1}$ & $H_{2}$ & $H_{3}$ & & Rasio \\
\hline 1 & 571 & 552 & 561 & 561,67 & 54,9819 \\
2 & 533 & 533 & 542 & 536,00 & 54,5825 \\
3 & 551 & 533 & 524 & 536,00 & 54,5776 \\
4 & 524 & 533 & 533 & 530,00 & 54,4847 \\
5 & 515 & 505 & 490 & 503,33 & 54,0316 \\
6 & 542 & 542 & 551 & 545,00 & 54,7217 \\
7 & 515 & 515 & 515 & 515,00 & 54,2361 \\
8 & 571 & 581 & 571 & 574,33 & 55,1824 \\
9 & 542 & 551 & 542 & 545,00 & 54,7271 \\
\hline
\end{tabular}

Catatan:

$\mathrm{E}=$ Eksperimen .

Tabel 5 . Ketangguhan dan signal / noise

\begin{tabular}{|c|c|c|c|c|}
\hline \multirow{2}{*}{ E } & \multicolumn{2}{|c|}{ Replikasi } & \multirow{2}{*}{$\bar{H}$} & \multirow{2}{*}{$\begin{array}{l}\mathrm{S} / \mathrm{N} \\
\text { Rasio }\end{array}$} \\
\hline & $H_{1}$ & $\mathrm{H}_{2}$ & & \\
\hline 1 & 20,00 & 18,00 & 19,00 & 25,54 \\
\hline 2 & 20,00 & 21,00 & 20,50 & 26,23 \\
\hline 3 & 22,00 & 25,00 & 23,50 & 27,37 \\
\hline 4 & 21,00 & 24,00 & 22,50 & 26,99 \\
\hline 5 & 29,00 & 30,00 & 29,50 & 29,39 \\
\hline
\end{tabular}

\begin{tabular}{lllll}
6 & 23,00 & 21,00 & 22,00 & 26,82 \\
7 & 29,00 & 30,00 & 29,50 & 29,39 \\
8 & 22,00 & 20,00 & 21,00 & 26,41 \\
9 & 28,00 & 29,00 & 28,50 & 29,09 \\
\hline
\end{tabular}

Tabel 6 Respon kekerasan rata rata

\begin{tabular}{cccc}
\hline$L$ & $A$ & $H$ & $T$ \\
\hline 1 & 544,44 & 535,44 & 560,11 \\
2 & 526,00 & 537,89 & 537,00 \\
3 & 544,78 & 541,89 & 518,11 \\
\hline Selisih & 18,78 & 6,44 & 42,00 \\
\hline Rank & 2 & 3 & 1 \\
\hline
\end{tabular}

Tabel 7 Respon ketangguhan rata rata

\begin{tabular}{cccc}
\hline$L$ & $A$ & $H$ & $T$ \\
\hline 1 & 21,00 & 23,67 & 20,67 \\
2 & 24,67 & 23,67 & 23,83 \\
3 & 26,33 & 24,67 & 27,50 \\
\hline Selisih & 5,33 & 1,00 & 6,83 \\
\hline Rank & 2 & 3 & 1 \\
\hline
\end{tabular}

Tabel 8 respon $\mathrm{S} / \mathrm{N}$ rasio kekerasan

\begin{tabular}{cccc}
\hline$L$ & $A$ & $H$ & $T$ \\
\hline 1 & 54,7140 & 54,56758 & 54,96202 \\
2 & 54,4127 & 54,59885 & 54,59810 \\
3 & 54,7152 & 54,67551 & 54,28181 \\
\hline Selisih & 0,30250 & 0,10790 & 0,68020 \\
\hline Rank & 2 & 3 & 1 \\
\hline
\end{tabular}

Tabel 9 Respon $\mathrm{S} / \mathrm{N}$ rasio kekerasan

\begin{tabular}{cccc}
\hline$L$ & $A$ & $H$ & $T$ \\
\hline 1 & 26,38 & 27,31 & 26,26 \\
2 & 27,73 & 27,34 & 27,44 \\
3 & 28,30 & 27,76 & 28,72 \\
\hline Selisih & 1,92 & 0,46 & 2,46 \\
\hline Rank & 2 & 3 & 1 \\
\hline
\end{tabular}

\section{Optimasi}

Dalam penelitian ini metode yang digunakan adalah metode Taguchi. Terdapat 4 langkah dalam metode Taguchi sebagai berikut.[8]

1. Pemilihan karakter kualitas.

Terdapat tiga macam karakter kualitas dalam metode Taguchi yaitu smaller, better dan larger adalah lebih baik.

2. Pemilihan faktor kontrol dan bebas.

Dalam penelitian ini dipilih faktor bebas se banyak 3 yaitu austenisasi (A), holding 
(H) dan tempering $(\mathrm{T})$. Sedang faktor Prediksi performa optimal

kontrolnya adalah kekerasan dan Pada perhitungan ANOVA, didapatkan hasil ketangguhan.

optimal dari tiap parameter. Kemudian berdasarkan hasil yang didapat, maka dilakukan per-

3. Pemilihan ortogonal array. Ada tiga pa-rameter dalam penelitian ini. hitungan nilai prediksi optimal untuk mengukur
Setiap parameter $(P)$ memiliki tiga level apakah uji konfirmasi masih dalam batas tole(L). Perhitungan derajat kebebasan (DK) ransi atau tidak. didapat derajat kebebasan sebanyak 6 sehingga orthogonal array yang dipilih harus sama atau lebih dari tiga.

Besar dari derajat kebebasannya. Ortogonal array yang memenuhi adalah L9 (33).

4. Pelaksanaan pengujian. Terdapat 9 eksperimen dalam penelitian ini dengan para-meter dan level yang berbeda-beda. Pengujian dilakukan pada mesin furnace. Setiap ekspe-rimen di sesuaikan dengan kondisi pada orto-gonal array. Spesimen yang digunakan ada-lah HRP Steel dengan kekerasan awal 286 HVN.

Pada tabel anova dapat dilihat persen kontribusi di masing-masing parameter, untuk kekerasan (Tabel 10) dan ketangguhan (Tabel 11) yang memiliki kontribusi terbesar adalah tempering. $F_{\text {hitung }}$ sebagai pembanding dengan $F$ tabel sehingga ada kedua kolom tersebut total dan error tidak dihitung. Jika Fitung lebih besar dari $\mathrm{F}$ tabel maka hipotesa bisa diterima.

\section{Anova}

Tabel 10. Anova kekerasan

\begin{tabular}{|c|c|c|c|c|c|c|}
\hline L & SS & DK & SM & $F_{H}$ & $F_{\text {Tot }}$ & $\mathrm{K}$ \\
\hline A & 2066,074 & 2,00 & 1033,037 & 9,45 & 3,49 & 16,54 \\
\hline H & 191,630 & 2,00 & 95,815 & 0,88 & 3,49 & 1,53 \\
\hline T & 8051,852 & 2,00 & 4025,926 & 36,85 & 3,49 & 64,44 \\
\hline Err. & 2185,185 & 20,00 & 109,259 & & & 17,49 \\
\hline Tot. & 12494,741 & 26,00 & & & & 100,00 \\
\hline
\end{tabular}

$\mathrm{F}_{\mathrm{H}}=$ Fungsi hitung; $\mathrm{F}_{\text {Tot }}=$ Fungsi total; $\mathrm{K}=$ Kontribusi

Tabel 11. Anova ketangguhan

\begin{tabular}{|c|c|c|c|c|c|c|}
\hline L & SS & DK & SM & $F_{H}$ & $F_{\text {Tot }}$ & K \\
\hline A & 89,333 & 1,00 & 89,333 & 24,85 & 4,60 & 31,46 \\
\hline H & 4,000 & 1,00 & 4,000 & 1,11 & 4,60 & 1,41 \\
\hline T & 140,333 & 1,00 & 140,333 & 39,03 & 4,60 & 49,41 \\
\hline Err & 50,333 & 14,00 & 3,595 & & & 17,72 \\
\hline Tot & 284,000 & 17,00 & & & & 100,00 \\
\hline
\end{tabular}

1. Prediksi kekerasan

$\mathrm{H}$ prediksi $=\mathrm{A}_{3}+\mathrm{B}_{3}+\mathrm{C}_{1}-2 \mathrm{y}$.

$\mathrm{H}$ prediksi $=544,78+541,89+560,11-$

$$
2 \times(538,41)
$$

$\mathrm{H}$ prediksi $=569,96(\mathrm{HVN})$

Interval kepercayaan.

$\eta_{\text {eff }}=\frac{\text { Jumlah total eksperimen }}{1+\text { jumlah DOF }}$

$\eta_{\text {eff }}=\frac{9 \times 3}{1+6}=3,86$

$C I= \pm \sqrt{F_{0,05 ; 2 ; 20} \times M S_{e} \times\left(\frac{1}{\eta_{e f f}}\right)}$

$$
C I= \pm \sqrt{3,49 \times 110,43 \times\left(\frac{1}{3,86}\right)}
$$

$C I= \pm 10$

$\mathrm{H}_{\text {prediksi }}=569,96 \pm 10(\mathrm{HVN})$

\section{Prediksi ketangguhan}

$\mathrm{H}$ prediksi $=\mathrm{A}_{3}+\mathrm{B}_{3}+\mathrm{C}_{1}-2 \mathrm{y}$.

$\mathrm{H}$ prediksi $=26,33+24,67+27,50-2 \times(24)$

$\mathrm{H}$ prediksi $=30,40(\mathrm{~J})$

Interval kepercayaan

$\eta_{\text {eff }}=\frac{\text { Jumlah total eksperimen }}{1+\text { jumlah DOF }}$

$\eta_{\text {eff }}=\frac{9 \times 3}{1+3}=6,75$

$C I= \pm \sqrt{F_{0,05 ; 1 ; 1,4} \times M S_{e} \times\left(\frac{1}{\eta_{e f f}}\right)}$

$$
\begin{aligned}
& C I= \pm \sqrt{4,60 \times 3,595 \times\left(\frac{1}{3,86}\right)} \\
& C I= \pm 1,57
\end{aligned}
$$

$\mathrm{H}_{\text {prediksi }}=30,50 \pm 1,57(\mathrm{~J})$ 


\section{KESIMPULAN}

Berdasarkan penelitian yang sudah dilakukan menunjukkan bahwa HRP Steel lokal tebal $10 \mathrm{~mm}$ bisa dikeraskan dengan mengacu pada kekerasan dan ketangguhan yang diinginkan, dan ini merupakan nilai optimum yang bisa dicapai.

Selanjutnya hasil penelitian dapat disimpulkan sebagai berikut:

1. Kondisi parameter optimum yang berpengaruh pada nilai kekerasan adalah austeni-sasi pada temperatur $900{ }^{\circ} \mathrm{C}$, holding time selama 45 menit, dan tempering pada $125{ }^{\circ} \mathrm{C}$ dengan nilai prediksi kekerasan sebesar 569,96 HVN. Parameter yang memberikan pengaruh terbesar pada kekerasan adalah tempering.

2. Kondisi optimal parameter yang berpengaruh pada nilai ketangguhan adalah austeni-sasi pada temperatur $900{ }^{\circ} \mathrm{C}$, holding time selama 45 menit, dan tempering pada $175{ }^{\circ} \mathrm{C}$ dengan nilai prediksi ketangguhan sebesar $30,50 \mathrm{~J}$. Parameter yang memberikan pengaruh terbesar pada ketangguhan adalah tempering.

\section{UCAPAN TERIMA KASIH}

Kepada Ir. Amung Somantri PT. Krakatau Steel (Persero), Cilegon, Banten, Indonesia atas ijin observasi dan bantuan bahan penelitian ini.

\section{DAFTAR PUSTAKA}

[1] K. O. Lee, S. K. Hong, Y. K. Kang, H. J. Yoon and S. S. Kang, 2009, Grain Refinement In Bearing Steels Using A Double Quenching, Heat-Treatment Process, International Journal of Automotive Technology, Vol. 10, No. 6, pp. 697-702.

[2] Sampath, 2007, How to Choose Electrodes for Joining High-Strength Steels, Welding Journal, hal $26-28$.

[3] Messler, Robert W., Jr., 2004, Princile of Welding (Processes, Physics, Chemistry, and Metallurgy), WILEY-VCH Verlag GmbH \& Co. KGaA, Weinheim, hal. 547.

[4] Bhadesia, H.K.D.H. \& Honeycombe, Robert, 2006, Steels (Microstructure and Properties), 3rd edition, Elsevier, Ltd. Oxford, hal. 116.

[5] Krauss, George.,1999, Martensite in steel: strength and structure, Materials Science and Engineering A273-275 (1999): 40-57.

[6] G. Luxenburger, M. Bockelmann, P. Wolf, F. Hanus, R. Cawelius, J. Buchholz, 2004, High strength quenched and tempered $(Q+T)$ steels for pressure vessels, International Journal of Pressure Vessels and Piping 81, $159-171$.

[7] C. Revilla, B. López, J.M. Rodriguez-lbabe, 2014, Carbide size refinement by controliing the heating rate during induction tempering in a low alloy steel, Materials and Design 62 (2014) 296-304.

[8] Soejanto, Irwan, 2009, Desain Eksperimen dengan Metode Taguchi, Jogjakarta, 2009. 